\title{
(C) \\ Portomesenteric venous gas and pneumatosis intestinalis secondary to mesenteric ischaemia
} OPEN ACCESS

James Vassallo, ${ }^{1}$ Julia Gauci, ${ }^{2}$ Kelvin Cortis ${ }^{3}$

${ }^{1}$ Mater Dei Hospital, Msida, Malta

${ }^{2}$ Foundation Programme, Mater Dei Hospital, Msida, Malta ${ }^{3}$ Department of Radiology, Mater Dei Hospital, Msida, Malta

Correspondence to Dr James Vassallo, james.vassallo18@gmail.com

Accepted 1 May 2016

\section{DESCRIPTION}

We describe a case of a 61-year-old Caucasian man who presented to the emergency department because of severe periumbilical pain associated with nausea and vomiting. On examination, there was gross distension with generalised tenderness, more prominent in the left iliac fossa. The patient was afebrile and parameters were stable.

Coronal and axial CT images showed extensive branching radiolucency extending to within $2 \mathrm{~cm}$ of the liver capsule, which is characteristic of portal venous gas (PVG) and differentiates it from pneumobilia (figure 1). Gas was also present throughout the superior mesenteric vein and its tributaries (closed arrow, figure 2B). A large portion of the small bowel wall showed band-like intramural gas (open arrow figure 2A), in keeping with pneumatosis intestinalis (PI).
A laparotomy was performed and $\sim 400 \mathrm{~cm}$ of infarcted small bowel resected with formation of a jejunostomy and mucous fistula. Intraoperatively, all arteries were found to be patent on palpation. Intestinal integrity was restored 2 months after the first surgery and after 5 months of inpatient care, the patient was discharged with short bowel syndrome.

The most common cause of PI and PVG is bowel ischaemia ( $70 \%$ of cases); however, with the increased use of CT imaging, both PI and PVG are being encountered more frequently and owing to several other conditions including mechanical causes such as complete or partial bowel obstruction, trauma, radiation and diverticulitis, as well as benign idiopathic causes such as recent surgery, inflammatory bowel disease and kayexalate use. ${ }^{1}$ Such findings therefore present a dilemma in the
A

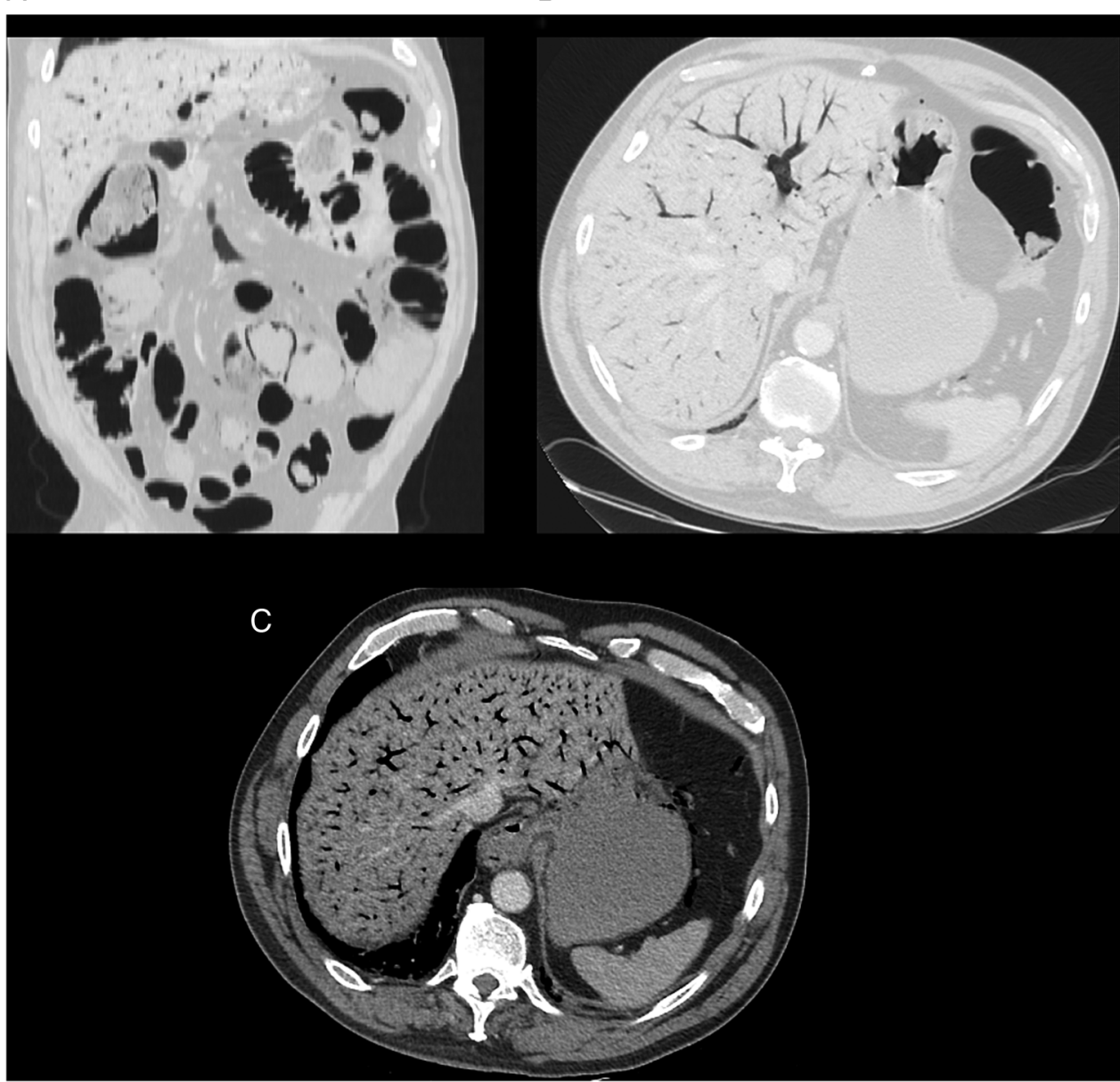

Cortis K. BMJ Case Rep Published online: [please include Day Month Year] doi:10.1136/bcr-2016215977

CrossMark

Figure 1 (A) Coronal reconstruction showing portal venous gas and dilated small bowel loops with band-like pneumatosis intestinalis; ( $B$ and $C$ ) showing extensive portal venous gas as well as gas within the stomach wall. 
Figure 2 (A) Showing dilated bowel loops with fluid levels and extensive pneumatosis intestinalis. The open arrow highlights the band-like distribution of gas within the bowel wall. The closed arrow in (B) showing gas with the tributaries of the superior mesenteric vein.

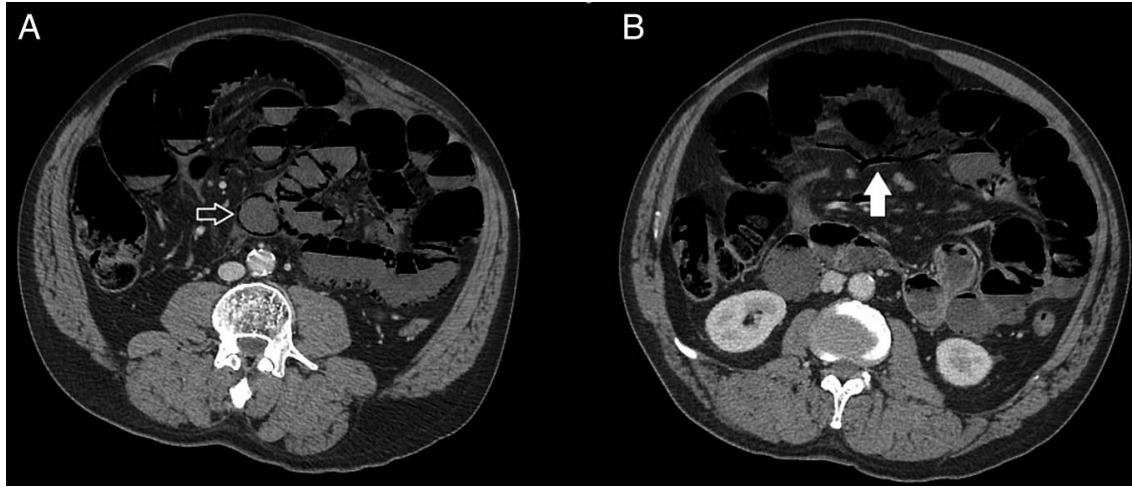

differential diagnosis and management of PVG; and/or PI as an exploratory laparotomy performed on all these patients would result in up to $30 \%$ of patients being subjected to an unnecessary procedure. ${ }^{2}$

Although ischaemic bowel carries a high mortality rate of up to $75-90 \%$, the presence or degree of PVG and PI does not necessarily confer a higher mortality rate. Both PVG and PI may occasionally be found even in patients with only partial mural bowel ischaemia. Therefore, neither PVG nor PI can be used to distinguish between transmural bowel infarction and only partial mural bowel ischaemia, if they are encountered as mild and isolated findings. However, transmural infarction of the affected

\section{Learning points}

- Although the most common cause of portal venous gas (PVG) or pneumatosis intestinalis (PI) is bowel ischaemia, several other benign causes have been identified and therefore a laparotomy is only indicated when suspecting intestinal ischaemia based on all the radiological and clinical findings.

- Transmural infarction is more likely in the presence of both PI and PVG, however, they do not necessarily indicate a worse prognosis and prompt surgical intervention is essential to achieving a favourable outcome. bowel does become likely if PI is pronounced and band like as opposed to bubble like and, more importantly, if it is combined with PVG, as in the case described. ${ }^{3}$

Currently, the basis for determining the mortality or morbidity in cases of PVG or PI is related to the underlying cause and not the presence or extent of these radiological findings. However, there are no data in the literature to suggest whether the presence of PVG or PI on CT is an indicator of an adverse prognosis in patients suffering from transmural infarction.

Contributors JV wrote up the manuscript and performed the literature review. JG contributed to the literature review and the editing of the images. KC supplied the images and reviewed the final manuscript.

Competing interests None declared.

Patient consent Obtained.

Provenance and peer review Not commissioned; externally peer reviewed.

Open Access This is an Open Access article distributed in accordance with the Creative Commons Attribution Non Commercial (CC BY-NC 4.0) license, which permits others to distribute, remix, adapt, build upon this work non-commercially, and license their derivative works on different terms, provided the original work is properly cited and the use is non-commercial. See: http://creativecommons.org/ licenses/by-nc/4.0/

\section{REFERENCES}

1 Sebastià C, Quiroga $S$, Espin E, et al. Portomesenteric vein gas: pathologic mechanisms, CT findings, and prognosis. RadioGraphics 2000;20:1213-24.

2 Wayne E, Ough M, Wu A, et al. Management algorithm for pneumatosis intestinalis and portal venous gas: treatment and outcome of 88 consecutive cases. J Gastrointest Surg 2010;14:437-48.

3 Hou SK, Chern $\mathrm{CH}$, How CK, et al. Hepatic portal venous gas: clinical significance of computed tomography findings. Am J Emerg Med 2004;22:214-18.

Copyright 2016 BMJ Publishing Group. All rights reserved. For permission to reuse any of this content visit http://group.bmj.com/group/rights-licensing/permissions.

BMJ Case Report Fellows may re-use this article for personal use and teaching without any further permission.

Become a Fellow of BMJ Case Reports today and you can:

- Submit as many cases as you like

- Enjoy fast sympathetic peer review and rapid publication of accepted articles

- Access all the published articles

- Re-use any of the published material for personal use and teaching without further permission

For information on Institutional Fellowships contact consortiasales@bmjgroup.com

Visit casereports.bmj.com for more articles like this and to become a Fellow 